\title{
EL PROCEDIMIENTO CONTENCIOSO TRIBUTARIO EN EL PERÚ BICENTENARIO DEL SIGLO XXI: ALGUNOS COMENTARIOS Y EL USO DE NUEVAS TECNOLOGÍAS ${ }^{* * *}$
}

\section{The contentious tax procedure in a Bicentennial Peru of the XXI century: some commentaries and new technologies}

Sergio Ezeta Carpio ${ }^{* *}$

Tribunal Fiscal

Las opiniones vertidas en el presente artículo son a título personal.

** El presente artículo ha sido escrito en el mes de marzo del año 2021, encontrándose vigente el Texto Único Ordenado del Código Tributario aprobado por Decreto Supremo № 133-2013-EF y normas modificatorias.

*** Vocal Presidente de la Sala 11 del Tribunal Fiscal del Ministerio de Economía y Finanzas. Abogado por la Pontificia Universidad Católica del Perú (PUCP). Diplomado en Tributación por la PUCP. Diplomado en Tributación por SUNAT - CIAT. Ha sido profesor de Derecho Tributario en la Universidad de Piura y dictado cursos sobre la misma materia en la PUCP, Universidad Nacional Mayor de San Marcos y Universidad de Lima, entre otras universidades. ORCID iD: 0000-0002-8135-7866. Contacto: sezeta@mef.gob.pe 


\section{Resumen:}

El artículo versa sobre el procedimiento contencioso tributario en el Perú. Luego de hacer una breve explicación del esquema actual, se resaltan algunos aspectos problemáticos y que deben ser corregidos o perfeccionados en la legislación, siempre encaminados a prestar un mejor servicio al ciudadano quien quiere contar con vías rápidas y eficientes a fin de poder ejercer su derecho de defensa y, como parte de él, su derecho a contradecir los actos administrativos (en este caso, emitidos por la Administración Tributaria) que, a su entender, afectan sus bienes o derechos de manera indebida.

Un tema actual que también se trata es el tránsito del expediente físico al expediente electrónico, qué se ha avanzado al respecto y qué se espera a futuro. En este punto se resalta el hecho que dicho tránsito se viene precipitando por la COVID-19, aunque ya había avances al respecto desde hace varios años. Se resalta la vinculación del expediente electrónico con un tema más general, el cual es el del gobierno digital (o gobierno electrónico).

\section{Abstract:}

The article deals with the contentious tax procedure in Peru. After making a brief explanation of the current scheme, some problematic aspects that must be corrected or perfected in the legislation are highlighted, always with the purpose of providing a better service to the citizens who wants to have fast and efficient ways to exercise their right of defense and, linked to it, their right to contradict administrative acts (in this case, issued by the Tax Administration) that, in their understanding, improperly affect their property or rights in an undue manner.

A current issue that is also discussed is the transition from the physical file to the electronic file, which has been advanced and is expected to be ready in the future. On this point, it is mentioned that due to the COVID-19 pandemic this process has been precipitated, although there had already been progress in this regard for several years. In addition, the connection between the electronic file and a more general issue, such as the digital government (or electronic government), is highlighted.

Palabras clave:

Procedimiento contencioso tributario - Expediente electrónico Gobierno digital - TIC - Domicilio procesal electrónico - Digitalización 


\section{Keywords:}

Contentious tax procedure - Electronic file - Digital government - TIC Electronic procedural address- Digitalization

\section{Sumario:}

1. Palabras preliminares - 2. Procedimientos regulados en el Código Tributario - 3. El procedimiento contencioso tributario: esquema general - 4 . Procedimiento contencioso tributario: TIC, gobierno digital y expediente electrónico - 5. Procedimiento contencioso tributario: ¿̇en qué se puede mejorar? -6 . Conclusiones -7 . Lista de referencias

\section{PALABRAS PRELIMINARES}

El fin de ciclos o etapas es una oportunidad para identificar lo bueno y lo malo que se ha hecho, a fin de iniciar el nuevo ciclo o etapa con la conciencia clara de qué cosas pueden mantenerse, desecharse o modificarse.

Nuestro país, el Perú, está terminando sus primeros dos siglos de vida como república independiente (contados desde la declaración de independencia por Don José de San Martín, el sábado 28 de julio de 1821), y está a punto de iniciar el tercero.

Es, entonces, oportuno revisar los distintos aspectos vinculados a las actividades que desarrolla el Estado, entre otros, los relacionados al ámbito tributario, siempre con la idea de detectar qué aspectos pueden mejorarse, en beneficio de sus ciudadanos.

En el presente trabajo, pretendemos, dentro del vastísimo campo de la tributación, analizar uno de los procedimientos regulados en el Código Tributario: el procedimiento contencioso tributario. Dentro de dicho análisis queremos resaltar algunos temas que, a nuestro entender, merecen una mejor regulación, a fin de prestar un mejor y más eficiente servicio a los administrados, donde el uso de las nuevas tecnologías de la información y comunicación (TIC) ya vienen desempeñando un papel preponderante, más aun en un escenario mundial afectado severamente por la COVID-19, en el que debe priorizarse el uso de las TIC para evitar o restringir la presencia física de los administrados y de los propios funcionarios públicos en las oficinas estatales, permitiendo, así, la tramitación de procedimientos a través de canales virtuales implementados por el Estado, encaminado forzosa, acelerada e inexorablemente hacia la figura del llamado gobierno digital (o electrónico). 


\section{PROCEDIMIENTOS REGULADOS EN EL CÓDIGO TRIBUTARIO}

El Texto Único Ordenado del Código Tributario (2013), aprobado por Decreto Supremo № 133-2013-EF, (en adelante, Código Tributario ${ }^{1}$ ) regula cuatro procedimientos tributarios en sede administrativa:

- Procedimiento de fiscalización.

- Procedimiento contencioso - tributario.

- Procedimiento no contencioso.

- Procedimiento de cobranza coactiva.

El procedimiento contencioso - tributario ${ }^{2}$ es el único que se inicia con una contienda o controversia, evidenciada cuando el sujeto (deudor tributario o tercero) a quien se dirige un determinado acto administrativo emitido por la Administración Tributaria (denominado "acto reclamable") manifiesta su voluntad de contradecirlo, a través de un recurso (reclamación o apelación de puro derecho), por no estar de acuerdo con su emisión, por diversas consideraciones, de hecho y/o de derecho.

Según el Centro Interamericano de Administraciones Tributarias (2020):

(...) El derecho a recurrir, no compartir o estar disconforme con las decisiones de la Administración Tributaria es irrenunciable para los contribuyentes. La existencia de un sistema de resolución de recursos equilibrado, ágil y respetuoso con los derechos de los contribuyentes favorece el cumplimiento voluntario y la aceptación social de los impuestos (p. 28).

1 El Texto Único Ordenado es un texto actualizado de un determinado cuerpo normativo, que considera todos los cambios efectuados hasta la fecha de publicación del Texto Único Ordenado. El Código Tributario vigente fue aprobado por Decreto Legislativo № 816, en 1996, habiéndose aprobado con posterioridad diversas modificaciones, lo que obligó a que se aprobara un primer Texto Único Ordenado en 1999 (mediante Decreto Supremo № 135-99-EF) y posteriormente un segundo Texto Único Ordenado, el año 2013 (Decreto Supremo № 133-2013-EF).

2 Es necesario aclarar que el procedimiento contencioso - tributario es un procedimiento distinto a lo que se denomina proceso contencioso administrativo, pues el primero es un procedimiento administrativo, es decir, se sigue en la vía administrativa (ya sea en etapa de reclamación ante la propia entidad que emitió el acto reclamable materia de impugnación, o en etapa de apelación, ante el Tribunal Fiscal), mientras que el proceso contencioso administrativo es un proceso judicial que se sigue a fin de cuestionar ante el Poder Judicial los pronunciamientos de la última instancia de la sede administrativa (que, en materia tributaria, es el Tribunal Fiscal). 
En este orden de ideas, más allá de salvaguardar el derecho de defensa de los deudores tributarios o terceros afectados por actos de la Administración Tributaria, la existencia de un sistema de resolución de recursos bien estructurado (representado, en sede administrativa, en la legislación peruana principalmente por el procedimiento contencioso tributario) constituye indirectamente un incentivo al cumplimiento voluntario de las obligaciones tributarias e incide en que los impuestos (incluso diríamos que los tributos en general) sean aceptados socialmente.

\section{EL PROCEDIMIENTO CONTENCIOSO TRIBUTARIO: ESQUEMA GENE- RAL}

Antes de hacer el ejercicio de identificar aspectos del Procedimiento Contencioso tributario que merecen ser regulados de mejor manera, resulta conveniente tener claro el esquema general de dicho procedimiento en la legislación nacional.

Así, tenemos que de acuerdo con lo dispuesto en el Código Tributario33, el procedimiento contencioso tributario se inicia con la interposición por parte del deudor tributario o un tercero con legítimo interés de un recurso de reclamación o de un recurso de apelación de puro derecho contra un acto reclamable, debidamente identificado. En el caso de actos reclamables que contienen deuda tributaria, salvo órdenes de pago, puede interponerse reclamación dentro del plazo señalado en el Código Tributario, sin necesidad de acreditarse el pago de la deuda tributaria impugnada o la presentación de carta fianza; vencido dicho plazo, el pago de la deuda tributaria impugnada o la presentación de carta fianza con respecto a la misma son ineludibles para que pueda admitirse el recurso presentado. La deuda tributaria vinculada a los aspectos no impugnados siempre debe pagarse para que se admita a trámite el recurso.

Ahora bien, no sólo es necesario identificar el acto contra el que se dirige el recurso, sino también que el recurso esté debidamente fundamentado. Es decir, que contenga las razones de hecho y de derecho por las cuales el recu-

3 El procedimiento contencioso tributario se encuentra regulado en los artículos 124 a 154 y 156 del Código Tributario. El artículo 155 regula la queja que se puede formular contra las actuaciones de la Administración Tributaria y del Tribunal Fiscal; sistemáticamente, debería estar ubicado en un Título distinto al del procedimiento contencioso tributario. 
rrente considera que el acto impugnado debe ser anulado, dejado sin efecto, modificado, etc.

Salvo cuando el recurso con el que se ha dado inicio al procedimiento contencioso tributario sea uno de puro derecho (donde no existen hechos que probar), existe un plazo probatorio, dentro del cual el recurrente podrá ofrecer y actuar las pruebas que juzgue necesarias (documentos, pericia e inspección por el encargado de resolver, que se valoran con las manifestaciones rendidas ante la Administración Tributaria).

Vencido el plazo probatorio, el órgano resolutor debe emitir y notificar al interesado la resolución respectiva, dando respuesta al recurso formulado. Aun cuando el procedimiento contencioso tributario se sigue casi en su totalidad por escrito, en la instancia de apelación existe la figura del informe oral, que pueden rendir las partes (Administración Tributaria y recurrente), a su pedido, ante el Tribunal Fiscal, en una misma fecha y hora. Basta que una de las partes pida el uso de la palabra (para rendir el informe oral), de manera oportuna, para que se haga la citación a ambas partes para la diligencia de informe oral, que puede realizarse con la asistencia de una o de las dos partes.

Luego de realizado el informe oral y vencido el plazo legalmente previsto para formular alegatos, el Tribunal Fiscal debe resolver el recurso de apelación interpuesto. Con la resolución del Tribunal Fiscal se agota la vía administrativa, pudiendo el recurrente ${ }^{4}$ impugnarla en la vía judicial a través de una demanda contencioso administrativa.

\section{PROCEDIMIENTO CONTENCIOSO TRIBUTARIO: TIC, GOBIERNO DI- GITAL Y EXPEDIENTE ELECTRÓNICO}

En las últimas décadas, se han producido grandes avances en el ámbito de las llamadas Tecnologías de la Información y la Comunicación (TIC), que han transformado las maneras en que los seres humanos nos relacionamos y comunicamos. Como dice Martínez Gutiérrez (2010):

(...) Nos encontramos actualmente en la denominada Sociedad de la Información, en la que la sociedad en general se ha habituado a la utilización cotidiana de las Tecnologías de la Información y de la Comunicación (...) para realizar todo tipo de actividades, sean públicas o privadas (...) (p.95).

4 Excepcionalmente, la Administración también puede interponer demanda contencioso administrativa. 
En esta sociedad de la información, nos comunicamos menos a través de documentos escritos en papel, y lo hacemos más enviándonos mensajes a través de diversas herramientas tecnológicas con las que accedemos al Internet o al correo electrónico desde cualquier lugar y en cualquier momento; ya no solamente computadoras, sino también teléfonos inteligentes o smartphones y tablets, muchos de los cuales tienen casi las mismas funciones que las computadoras, haciendo uso de múltiples programas y aplicaciones, como WhatsApp, Skype, Twitter, Instagram, Facebook, LinkedIn, etc. Asimismo, el uso de video llamadas y video conferencias a través de diversas herramientas tecnológicas (Zoom, Google Meet, Microsoft Teams, entre otras) se ha tornado en algo cotidiano, en los ámbitos público y privado, especialmente a partir de marzo del 2020, a fin de evitar el contacto físico entre las personas como medida preventiva para evitar la propagación de la temida COVID-19.

El Derecho no puede ser ajeno a esta coyuntura, sino que, por el contrario, debe adaptarse a los cambios en las relaciones humanas vinculados a los avances tecnológicos y a una crisis sanitaria global, regulando así las nuevas formas de relacionarse; asimismo, adecuando los principios y normas existentes, pensadas para un contexto de comunicación escrita en papel, a otro contexto muy diferente, donde el uso de las nuevas tecnologías es intensivo y generalizado.

En el ámbito del Derecho Administrativo, que es el que regula la organización del Estado, así como las relaciones que se dan entre los ciudadanos y el Estado, en ejercicio de sus funciones como tal, también se debe aprovechar estas nuevas tecnologías para proporcionar un mayor bienestar a los ciudadanos, a través de servicios que se presten de manera más eficiente y expeditiva, y desde cualquier lugar y en cualquier momento en que pueda accederse a las TIC.

El expediente electrónico tiene directa vinculación con el desarrollo de las TIC evidenciado en los últimos años, que, en muchos países del orbe - así como en organismos internacionales - ha propiciado que se constituyan comisiones o grupos de trabajo dirigidos a diseñar una regulación especial que rija lo que en términos generales se conoce como gobierno electrónico, gobierno digital o administración electrónica ${ }^{5}$.

Si bien algunos autores consideran que el término correcto para designar la interacción del Estado con sus ciudadanos a través de las TIC es el de administración electrónica, los países utilizan distintas denominaciones para referirse a la misma institución, como 
En el Perú, desde fines del siglo XX se han dado importantes avances en lo que respecta a la aplicación de las TIC en los servicios de la Administración Pública ${ }^{6}$ (incluyendo, por supuesto, a la Administración Tributaria), que han conllevado a la aprobación de diversas normas orientadas a regular toda una serie de servicios que la Administración presta, valiéndose de las nuevas tecnologías, así como también al establecimiento de obligaciones formales

gobierno electrónico, gobierno digital, e-government, governo electrónico, digital government, gobierno en línea, entre otras [Énfasis agregado].

6 Entre las medidas adoptadas en las últimas décadas para mejorar los servicios que presta el Estado con la ayuda de las TIC, podemos mencionar las siguientes:

- $\quad$ Año 1991: Decreto Legislativo № 681 y su reglamento (sobre uso de tecnologías avanzadas en materia de archivo de documentos e información);

- $\quad$ Año 2000: Ley № 27269, Ley de Firmas y Certificados Digitales y modificatorias;

- Año 2001: Resolución Ministerial № 61-2001-PCM - Aprueban lineamientos que establecen el contenido mínimo de los Planes Estratégicos de Gobierno Electrónico;

- $\quad$ Año 2001: Decreto Supremo № 060-2001-PCM- Crea el Portal del Estado Peruano;

- $\quad$ Año 2002: Ley № 27658, Ley Marco de Modernización de Gestión del Estado y modificatorias;

- Año 2002: Resolución Ministerial № 266-2002-PCM - Encarga preparación de la "Estrategia Nacional de Gobierno Electrónico" a la Secretaría de Gestión Pública de la Presidencia del Consejo de Ministros;

- $\quad$ Año 2007: Decreto Supremo № 019-2007-PCM - Sobre Ventanilla Única del Estado

- $\quad$ Año 2008: Decreto Supremo № 052-2008-PCM - Reglamento de la Ley de Firmas y Certificados Digitales y modificatorias;

- $\quad$ Año 2008: Resolución Ministerial № 381-2008-PCM - Aprueba los lineamientos y mecanismos establecidos en el documento "Estándares y Especificaciones de Interoperabilidad del Estado Peruano;

- $\quad$ Año 2010: Decreto Supremo № 010-2010-MINCETUR - Sobre Ventanilla Única de Comercio Exterior - VUCE;

- Año 2011: Decreto Supremo № 066-2011-PCM - Se aprueba el Plan de Desarrollo de Sociedad de la Información en el Perú - La Agenda Digital Peruana 2.0;

- Año 2013: Decreto Supremo № 004-2013-PCM- Aprueba la Política Nacional de Modernización de la Gestión Pública;

- $\quad$ Año 2013: Decreto Supremo № 081-2013-PCM - Se aprueba la Política Nacional de Gobierno electrónico;

- $\quad$ Año 2015: Resolución Ministerial № 176-2015-PCM- Aprueban el Plan de Acción de Gobierno Abierto 2015 - 2016;

- Año 2016: Decretos Legislativos № 1246, 1263, 1272 y 1310 (modificaciones a la Ley del Procedimiento Administrativo General y al Código Tributario, que incluyen normas sobre el procedimiento administrativo electrónico, expediente electrónico, interoperabilidad y simplificación administrativa, entre otras).

- $\quad$ Año 2018: Decreto Legislativo № 1412, Ley de Gobierno Digital. 
que se cumplen por medios electrónicos (libros electrónicos, comprobantes electrónicos y declaraciones electrónicas, entre otras).

Específicamente, en el ámbito de los procedimientos tributarios que se siguen o inician ante la Superintendencia Nacional de Aduanas y de Administración Tributaria (SUNAT), el expediente electrónico se ha vuelto realidad, en lo que respecta al procedimiento de cobranza coactiva, procedimiento de fiscalización y procedimiento contencioso tributario (sobre este último, en lo que respecta a la fase de reclamación $n^{7}$ ).

Aun cuando no todos los procedimientos mencionados se siguen electrónicamente en su integridad ${ }^{8}$, constituye un gran avance hacia la digitalización de los procedimientos la incorporación de los procedimientos mencionados en la regulación sobre el expediente electrónico de la SUNAT.

En cuanto a la fase del procedimiento contencioso tributario referida a la apelación ante el Tribunal Fiscal, si bien es cierto que aún no se sigue a través de un expediente electrónico, en los últimos años, se ha dado pasos importantes encaminados a tal objetivo. Por ejemplo: la notificación electrónica de las resoluciones emitidas por dicho colegiado ${ }^{9}$, el establecimiento de una mesa de partes virtual del Tribunal Fiscal y el uso de herramientas de video conferencia para diversas actividades ${ }^{10}$, como las consultas de las partes del procedimiento a los Secretarios Relatores de Sala sobre el estado de sus expedientes, los informes

7 Sobre la regulación del expediente electrónico en el ámbito de la SUNAT, puede revisarse la Resolución de Superintendencia № 084-2016/SUNAT, publicada el 23 de marzo de 2016 en el diario oficial "El Peruano", mediante la cual se aprobó el Sistema Integrado del Expediente Virtual (SIEV), y en especial su modificatoria, aprobada por Resolución de Superintendencia № 190-2020/SUNAT, publicada en el diario oficial "El Peruano" el 31 de octubre de 2020, que incorpora al SIEV los expedientes electrónicos de reclamación. Asimismo, el 25 de febrero de 2021 se publicó en el diario oficial "El Peruano", la Resolución de Superintendencia № 031-2021/SUNAT, que modificó la Resolución de Superintendencia $N^{\circ}$ 084-2016/SUNAT respecto a la presentación de escritos de reclamación, otros escritos y de solicitudes vinculadas a expedientes electrónicos de reclamación, a través de la Mesa de Partes Virtual de la SUNAT.

$8 \quad$ Salvo el procedimiento de fiscalización parcial electrónica.

9 Actualmente, la notificación electrónica de los actos emitidos por el Tribunal Fiscal se regula por la Resolución Ministerial № 205-2020-EF/40, publicada el 17 de julio de 2020 en el diario oficial "El Peruano".

10 Puede verse al respecto en la página web del Tribunal Fiscal (www.mef.gob.pe) los Acuerdos de Sala Plena № 06-2020, 11-2020, 12-2020, 13-2020, 14-2020, 16-2020, $17-2020$ y $18-2020$. 
orales que pueden rendirse ante los Vocales del Tribunal Fiscal y las sesiones de Sala ${ }^{11}$ o de Sala Plena ${ }^{12}$. Asimismo, recientemente, mediante Acuerdo de Sala Plena № 2021-02 del 3 de marzo de 2021, se han aprobado importantes reglas sobre la firma digital de los actos emitidos por el Tribunal Fiscal.

\section{PROCEDIMIENTO CONTENCIOSO TRIBUTARIO: ¿EN QUÉ PUEDE MEJORAR?}

Cuando tanto la Administración Tributaria como el Tribunal Fiscal ejercen su facultad resolutora en el marco del procedimiento contencioso tributario, están a su vez prestando un servicio a los administrados. En este caso, deudores tributarios o terceros ajenos a la relación jurídico tributaria, que cuestionan un acto administrativo por considerar que afecta indebidamente sus derechos o intereses, acuden a dichas instancias - en ejercicio de su derecho de defensa, reconocido constitucionalmente- para iniciar o seguir en segunda instancia una contienda generada por su discrepancia con un acto emitido por la Administración Tributaria, para lo cual las normas las normas vigentes los dotan de las garantías comprendidas en el debido procedimiento administrativo, principio recogido en el artículo IV del Título Preliminar del Texto Único Ordenado de la Ley del Procedimiento Administrativo General aprobado por Decreto Supremo № 004-2019-JUS ${ }^{13}$.

En este orden de ideas, la facultad resolutora de la que está investida la Administración Tributaria (y el Tribunal Fiscal) como parte de las trascendentales funciones que debe ejercer para que el tributo legalmente creado se convierta en un tributo efectivamente percibido ${ }^{14}$ por el Estado, así como el derecho de

11 Actualmente, el Tribunal Fiscal del Perú cuenta con 12 Salas, cada una de las cuales está conformada por tres Vocales.

12 La Sala Plena está conformada por todos los Vocales del Tribunal Fiscal.

13 "1.2. Principio del debido procedimiento.- Los administrados gozan de los derechos y garantías implícitos al debido procedimiento administrativo. Tales derechos y garantías comprenden, de modo enunciativo mas no limitativo, los derechos a ser notificados; a acceder al expediente; a refutar los cargos imputados; a exponer argumentos y a presentar alegatos complementarios; a ofrecer y a producir pruebas; a solicitar el uso de la palabra, cuando corresponda; a obtener una decisión motivada, fundada en derecho, emitida por autoridad competente, y en un plazo razonable; y, a impugnar las decisiones que los afecten (...)" (Decreto Supremo № 004-2019-JUS, 2019).

14 El maestro argentino Héctor Villegas (2002) señala que el Derecho Tributario Formal suministra las reglas de cómo debe procederse para que el tributo legislativamente 
defensa del administrado en que se ampara para cuestionar un acto con el que no está de acuerdo, total o parcialmente, son dos caras de la misma moneda, que vendría a ser precisamente el procedimiento contencioso tributario.

Por ello, cuando se analiza qué puede mejorarse en el procedimiento contencioso tributario, debe tenerse presente que éste es un medio para que el administrado, como recurrente, pueda plantear sus pretensiones, en salvaguarda de su derecho de defensa y del debido procedimiento, y para que la Administración Tributaria y el Tribunal Fiscal puedan resolver la controversia planteada contra un acto emitido por dicha Administración, ello conforme a las normas vigentes y buscando la verdad material, con el objetivo que el Estado recaude lo que le corresponda acorde con lo previsto en las leyes y reglamentos tributarios.

\subsection{Simplificación y estabilidad del sistema tributario}

Si bien estos aspectos no tienen relación exclusiva con el procedimiento contencioso tributario, sino con el sistema tributario en general, son características que, si se presentaran, permitirían la existencia de menos situaciones de conflicto o controversia; ergo, menos procedimientos.

Esto significaría que los deudores tributarios tendrían una mayor claridad acerca de sus derechos y obligaciones tributarias, y en su mayoría no requerirían acudir a las instancias administrativas (o judiciales, de ser el caso) para definir sus dudas interpretativas. En todo caso, los que acudieran a dichas instancias recibirían un mejor y oportuno servicio porque no debería producirse un exceso de carga procesal, se minimizaría la posibilidad de dualidades de criterio y la permanencia en el tiempo de las normas que conforman el sistema tributario permitiría que los administrados y los propios funcionarios de la Administración puedan conocerlas y asimilarlas mejor. Si no se pudiera evitar el conflicto, al menos podría tenerse la certeza que éste tendría una solución oportuna.

En el marco de la simplificación y estabilización del sistema tributario, sería recomendable incorporar, a nivel constitucional, una disposición que establez-

creado se transforme en tributo fiscalmente percibido. Coincido con Villegas, aunque considero también que la facultad resolutora, que viene a formar parte del Derecho Procesal Tributario, apunta al mismo objetivo, en el escenario que el tributo haya sido impugnado. Mientras más eficiente y oportuno sea el ejercicio de la facultad resolutora, podrá definirse más prontamente qué tributos efectivamente le corresponde cobrar al Estado, entre los que han sido impugnados (p. 393). 
ca que las normas que crean o modifican tributos deben entrar en vigencia transcurrido un tiempo razonable para que los operadores del derecho tributario puedan conocer a cabalidad las normas nuevas ${ }^{15}{ }^{16}$. Asimismo, debería reglamentarse la publicación de ediciones extraordinarias del diario oficial "El Peruano", a fin de que solo pueda publicarse en dichas ediciones normas cuya publicación es urgente, por algún motivo específico (por ejemplo, normas sobre salud pública), evitándose el uso indiscriminado de tales ediciones especiales, que en la práctica pasan a ser ediciones ordinarias y no extraordinarias porque se publican casi todos los días, desde hace algún tiempo atrás, incluyendo en ocasiones normas de índole tributaria.

15 Actualmente, únicamente en el caso de normas sobre tributos de periodicidad anual (como, por ejemplo, el Impuesto a la Renta), el artículo 74 de la Constitución establece que rigen a partir del 1 de enero del año siguiente a su promulgación, lo que denotaría una intención en la norma constitucional de que los operadores del derecho tomen conocimiento de la nueva norma con la debida antelación. Sin embargo, a lo largo de los años, se hizo costumbre en el Perú que las modificaciones a dichos tributos (especialmente al Impuesto a la Renta) se hiciesen los últimos días del año anterior (muchas veces, las normas se publicaban el 30 o 31 de diciembre), por lo que los operadores del derecho no contaban con el tiempo debido para analizar y aplicar debidamente la norma nueva.

16 Si bien el artículo 14 del Reglamento que establece disposiciones relativas a la Publicidad, Publicación de Proyectos Normativos y Difusión de Normas Legales de Carácter General, aprobado por Decreto Supremo № 001-2019-JUS (2019), señala que "las entidades públicas dispondrán la publicación de los proyectos de normas de carácter general que sean de su competencia en el Diario Oficial El Peruano, en sus Portales Electrónicos o mediante cualquier otro medio, en un plazo no menor de treinta (30) días antes de la fecha prevista para su entrada en vigencia, salvo casos excepcionales" y que "(...) Dichas entidades permitirán que las personas interesadas formulen comentarios sobre las medidas propuestas", el numeral 3.1 del citado artículo establece que la referida publicación de los proyectos de normas no se aplica a normas del Poder Legislativo a Decretos Legislativos, entre otras normas. En tal sentido, los proyectos de las Leyes y Decretos Legislativos (incluyendo los que regulan tributos) no tendrían que ser publicados. Con respecto a las normas tributarias de menor jerarquía que las Leyes, como por ejemplo Decretos Supremos o Resoluciones de Superintendencia de la SUNAT, sí se tiene la obligación de la prepublicación, salvo que la entidad emisora de la norma considere aplicable la excepción a la publicación de los proyectos prevista en el numeral 3.2 del citado artículo 14 ("Cuando la entidad por razones debidamente fundamentadas, en el proyecto de norma, considere que la prepublicación de la norma es impracticable, innecesaria o contraría a la seguridad o al interés público"). 


\subsection{Impulsar la digitalización de todas las etapas del procedimiento contencioso tributario, aunque sin eliminar la posibilidad de iniciarlo por medios físicos}

Si bien es cierto que el Perú es un país en que el acceso a Internet y el uso de herramientas tecnológicas ha aumentado en los últimos tiempos, especialmente por la problemática sanitaria mundial originada por la COVID-19, que ha conllevado a que un número importante de ciudadanos se haya visto obligado a desarrollar sus actividades laborales, profesionales y educativas (ya sea como docentes o como estudiantes) desde sus hogares, todavía existe un grupo que no tiene acceso a Internet o desconoce cómo utilizarla, o que no sabe manejar herramientas tecnológicas. Esto a raíz de que simplemente no son lo que se conoce como nativos digitales (entendiendo como tales a las personas que desde pequeños han estado acostumbrados al uso de herramientas tecnológicas para comunicarse e informarse) o no han tenido mayor necesidad de incorporar en su vida personal, profesional o laboral tales herramientas.

A propósito de lo antes expuesto, es de resaltar que el texto vigente de la Ley del Procedimiento Administrativo Genera ${ }^{17}{ }^{17}$ de aplicación supletoria en los procedimientos tributarios, regula en su artículo 30 el llamado Procedimiento Administrativo Electrónico (PAE), y señala, entre otras cosas, que el PAE debe prever las medidas pertinentes cuando el administrado no tenga acceso a medios electrónicos. Esta norma es de especial relevancia porque, como se ha indicado, si bien un número importante de la población puede tener acceso a instrumentos tecnológicos que les permita hacer uso de las ventajas del expediente electrónico, lo cierto es que no todos tienen acceso a ellos (ya sea temporal o permanentemente, por motivos económicos u otros), por lo que, de acuerdo con el principio de igualdad, el Estado debe procurar que todos los administrados puedan tener siempre la opción de iniciar un PAE o de presentar algún documento en el mismo, facilitándoles el ingreso a la página web respectiva en módulos de acceso que deben estar ubicados, de preferencia, en todas las oficinas administrativas, debiendo contar además con la asesoría de personal de la Administración que lo oriente en el uso y manejo de las TIC necesarias para el ingreso al PAE.

Adicionalmente, la legislación sobre el PAE siempre debe prever un mecanismo alternativo para que los administrados puedan iniciar o proseguir

17 Texto Único Ordenado de la Ley del Procedimiento Administrativo General aprobado por Decreto Supremo № 004-2019-JUS. 
un procedimiento por medios físicos, ya sea porque se ha producido algún problema con el sistema de la Administración al que debe accederse para iniciar el PAE o presentar algún documento en el PAE que impida ello porque la oficina de la Administración se encuentra en un lugar alejado donde no existe Internet permanentemente o porque el administrado, por falta de capacitación (analfabeto digital), quiere seguir el procedimiento tradicional.

En tal sentido, se hace indispensable que exista una etapa de transición del expediente físico al expediente digital, en la que se permita iniciar los procedimientos por medios físicos, y que en las oficinas de la Administración se asignen orientadores que enseñen a los administrados como hacer uso del sistema informático del expediente electrónico, cuando así lo requieran. Incluso, debe considerarse que las TIC no son infalibles, por lo que, ante problemas en los sistemas, siempre debe contarse con la alternativa de realizar actuaciones ante la Administración por medios físicos.

En otras palabras, la tecnología debe servir al ciudadano para tener un mejor servicio administrativo, pero nunca debe limitar el ejercicio de los derechos recogidos en las normas vigentes.

\subsection{Debe perfeccionarse la regulación sobre el domicilio procesal elec- trónico}

Tal como mencionábamos en otro trabajo:

La notificación es una institución jurídica fundamental, especialmente en las ramas del Derecho que tienen por objeto principal de estudio los procesos judiciales o los procedimientos administrativos, y tiene estrecha vinculación con el Principio del Debido Proceso (o Debido Procedimiento, en el ámbito administrativo), como garantía de la toma de conocimiento por parte del interesado del contenido del acto emitido por la autoridad judicial o administrativa, lo que le permitirá ejercer, de considerarlo conveniente, su derecho de defensa, impugnando dicho acto, teniendo derecho en el procedimiento a exponer sus argumentos, a ofrecer y producir pruebas y a obtener una decisión motivada y fundada en derecho (...) (Ezeta, 2015).

Estrechamente vinculado con la temática sobre las notificaciones, como actuaciones a través de las cuales se pone en conocimiento de los administrados actos de la Administración que afectan sus derechos o intereses, se encuentra todo lo concerniente a la fijación de domicilios fiscales y domicilios procesales, pues en ellos es que debe realizarse efectivamente la notificación. 
En lo que respecta al domicilio procesal, el Código Tributario contempla en su artículo 11 que los administrados pueden fijarlo en los procedimientos que inician ante la Administración Tributaria. Con anterioridad a la regulación sobre el domicilio procesal electrónico, incorporada por el Decreto Legislativo № 1263 , de fines del 2016, los deudores tributarios o terceros tenían el derecho a fijar un domicilio procesal físico en los procedimientos tributarios, cuyo ejercicio era voluntario, dado que si no lo fijaban, las notificaciones se realizaban en el domicilio fiscal.

El Decreto Legislativo № 1263 incorporó la figura del domicilio procesal electrónico, modificando el segundo párrafo del citado artículo 11 en los siguientes términos:

(...) El domicilio fiscal es el lugar fijado dentro del territorio nacional para todo efecto tributario; sin perjuicio de la facultad del sujeto obligado a inscribirse ante la Administración Tributaria de señalar expresamente un domicilio procesal en cada uno de los procedimientos regulados en el Libro Tercero del presente Código con excepción de aquel a que se refiere el numeral 1 del artículo 112. El domicilio procesal podrá ser físico, en cuyo caso será un lugar fijo ubicado dentro del radio urbano que señale la Administración Tributaria, o electrónico, en cuyo caso, será el buzón electrónico habilitado para efectuar la notificación electrónica de los actos administrativos a que se refiere el inciso b) del artículo 104 y asignado a cada administrado, de acuerdo a lo establecido por resolución de superintendencia para el caso de procedimientos seguidos ante la SUNAT, o mediante resolución ministerial del Sector Economía y Finanzas para el caso de procedimientos seguidos ante el Tribunal Fiscal (...) Cuando de acuerdo a lo establecido por resolución de superintendencia, en el caso de procedimientos ante SUNAT o resolución ministerial, en el caso de procedimientos ante el Tribunal Fiscal, la notificación de los actos administrativos pueda o deba realizarse de acuerdo al inciso b) del artículo 104, no tiene efecto el señalamiento del domicilio procesal físico (...) [Énfasis agregado].

Sería recomendable ajustar un tanto la redacción de la norma citada porque con el texto actual, si bien, por un lado, parecería desprenderse que es el administrado quien puede optar por señalar un domicilio procesal, ya sea físico o electrónico, por otro lado, se deduce que en realidad no existe tal opción. Al contrario, existen escenarios en los que el recurrente necesariamente debe optar por el domicilio procesal electrónico y, de otro lado, no queda claro tampoco cuál es la naturaleza del domicilio electrónico cuando se realiza la notificación en el buzón electrónico, pero fuera de un procedimiento (por ejemplo, cuando se notifican resoluciones de determinación). 
Resulta de vital importancia que las normas sobre domicilio procesal electrónico sean lo más claras posibles, a fin de no perjudicar el derecho de defensa de los administrados, más aun cuando el domicilio procesal electrónico, junto con la notificación electrónica, son dos figuras procesales cuyo uso está camino a generalizarse, especialmente por la COVID-19, a fin de evitar diligencias de notificación presenciales, salvaguardando la salud de notificadores y deudores tributarios.

\subsection{Uso de la palabra}

Con respecto al pedido de uso de la palabra ante el Tribunal Fiscal, regulado en el artículo 150 del Código Tributario, durante los primeros años de vigencia del referido texto normativo, las partes ${ }^{18}$ no podían solicitarlo, sino que era decisión de dicho cuerpo colegiado citarlas o no para tal efecto, se entiende, en función a la mayor o menor complejidad de la materia en controversia.

Al respecto, sería conveniente incluir entre los supuestos en que no procede conceder el uso de la palabra los casos en que la controversia que se eleva al Tribunal Fiscal está referida a declaraciones de inadmisibilidad, ya sea de la reclamación o de la apelación. La audiencia de informe oral debería reservarse para casos en que se va a dilucidar cuestiones de fondo, pues normalmente el cumplimiento o no de requisitos de admisibilidad se evalúa en base a un análisis meramente objetivo, que no exige un profundo análisis sobre el particular, a diferencia de las controversias de fondo.

Asimismo, sería recomendable eliminar el derecho a uso de la palabra en los procedimientos sumarios (por ejemplo, referidos a tercerías de propiedad o cierres de establecimiento, entre otros), dada la importancia de que tales procedimientos se resuelvan en un término breve, especialmente por la naturaleza de la controversia (referida a derecho de propiedad, al cierre temporal de un negocio, etc.), y lamentablemente la citación a informe oral origina que se extienda el plazo que se toma el Tribunal Fiscal para emitir pronunciamiento en tales casos sumarios. Es de resaltar que el hecho que no se conceda legalmente el derecho de uso de la palabra no constituye una violación al derecho de defensa, sino que implica que éste deberá ser ejercido únicamente por escrito, como por ejemplo ocurre actualmente en el caso de las quejas, en las cuales no procede solicitar el uso de la palabra.

18 En la instancia de apelación, son partes del procedimiento tanto el recurrente como la Administración Tributaria. 


\subsection{Impugnación de Órdenes de Pago}

Las Órdenes de Pago son actos que puede emitir la Administración Tributaria en los supuestos previstos en el artículo 78 del Código Tributario, en virtud del cual se cobra al deudor tributario tributos o pagos a cuenta autoliquidados, 0 tributos derivados de errores materiales de redacción o de cálculo, entre otros.

En los recursos de reclamación contra Órdenes de Pago rige, principalmente, solve et repete (pague primero y reclame después), a diferencia de lo que ocurre en la impugnación de otros valores, como las Resoluciones de Determinación y las Resoluciones de Multa, para cuya impugnación no se exige el pago de la deuda tributaria impugnada, siempre que se formule en el plazo previsto legalmente. Fuera del mismo, debe pagarse la deuda impugnada o presentarse carta fianza por su monto actualizado de acuerdo con las reglas previstas en el Código Tributario.

Sin embargo, en materia de reclamación de Órdenes de Pago, el Código Tributario contempla dos supuestos, dependiendo si existen o no circunstancias que evidencien la improcedencia de su cobranza:

i. Cuando no existen circunstancias (artículo 136 del Código Tributario): Se aplica la regla solve et repete, es decir, debe pagarse la totalidad de la deuda tributaria que contiene la Orden de Pago, para que pueda admitirse el recurso.

ii. Cuando sí existen circunstancias (artículo 119 del Código Tributario): Si existen circunstancias que evidencien improcedencia de cobro de la orden de pago, la reclamación puede presentarse dentro del plazo de 20 días hábiles. La Administración tiene un plazo máximo para resolver esta reclamación de 90 días hábiles. Asimismo, el citado artículo 119 prevé como requisito de admisibilidad el pago de la parte de la deuda tributaria no impugnada; a contrario sensu, el pago de la deuda impugnada no es requisito de admisibilidad.

Sin embargo, la particularidad de este segundo supuesto es la existencia de circunstancias que evidenciarían la improcedencia de la cobranza, y ello recién se va a corroborar al presentar el recurso de reclamación respectivo y se acrediten tales circunstancias.

Sería recomendable que se modifique la norma, a fin de establecer que en ambos supuestos no se aplica el solve et repete, siempre que se formule el recurso de reclamación en un plazo determinado (que podría ser de 20 días hábiles), siendo que, si se cumple con ello y se prueba la existencia de tales circunstancias, la lógica consecuencia debería ser declarar fundada la reclama- 
ción y dejar sin efecto la Orden de Pago, mientras que si las circunstancias no son acreditadas, debería declararse infundada la reclamación.

\subsection{Actos no Reclamables}

Así como el artículo 135 del Código Tributario establece qué actos califican como reclamables, incluyendo un cajón de sastre, constituido por un concepto jurídico indeterminado, según el cual son reclamables también los "(...) los actos que tengan relación directa con la determinación de la deuda Tributaria $(. . .)^{\prime \prime 19}$, sería recomendable que, de manera ilustrativa, el citado Código también mencione una lista, no taxativa, de actos no reclamables, en función a casos que se han presentado a lo largo de los años, pudiendo incluirse como actos no reclamables, entre otros, las resoluciones coactivas, los requerimientos de fiscalización y los requerimientos de admisibilidad. Si bien ya existe jurisprudencia del Tribunal Fiscal que establece que tales actos no son reclamables ${ }^{20}$, incluirlos en el Código Tributario podría ayudar a que el grueso de la población, que no necesariamente cuenta con asesoría especializada, sepa que la impugnación de determinados actos en la vía de reclamación, en el marco del procedimiento contencioso tributario, no resulta procedente, por lo que se ahorraría valioso tiempo que muchas veces se insume innecesariamente en la tramitación de procedimientos infructuosos, al haberse utilizado una vía no apropiada para cuestionar tales actos.

\subsection{Resoluciones de cumplimiento del Tribunal Fiscal: ¿qué ocurre cuando la Administración no emite la resolución en cumplimiento de lo ordenado por el Tribunal Fiscal dentro del plazo previsto en el artículo 156 del Código Tributario?}

Cuando la Administración Tributaria no resuelve los recursos de reclamación dentro del plazo previsto en el Código Tributario, éste prevé que el recurrente pueda acogerse al silencio administrativo negativo, es decir, asumir que la Administración ha desestimado su recurso, y formular apelación contra la resolución ficta denegatoria de la reclamación. De esta manera, para acogerse al silencio negativo es necesario que se cumplan dos requisitos:

- Que transcurra el plazo previsto legalmente sin que la Administración haya notificado su decisión al recurrente; y

19 Informe № 36- 2009-SUNAT/2B4000.

20 Entre otras, las Resoluciones № 14148-11-2011, 01861-3-2015 y 03398-Q-2019. 
- Que el recurrente manifieste su voluntad de acogerse al silencio negativo, presentando el recurso de apelación contra la ficta denegatoria.

Es pertinente mencionar que el Tribunal Fisca ${ }^{21}$ ha considerado improcedente la queja formulada por el recurrente contra la Administración Tributaria por no resolver oportunamente su recurso de reclamación, debido a que, de conformidad con el criterio adoptado por este Tribunal en la Resolución $\mathrm{N}^{\circ}$ 13990-1-2010, entre otras, en virtud del silencio administrativo negativo regulado por las normas del Código Tributario, el contribuyente tiene el derecho de dar por denegada la reclamación que presentó e interponer la apelación correspondiente.

Así, la demora de la Administración en resolver dicho recurso no corresponde ser planteada en vía de queja. Agrega el Tribunal que, si bien la queja constituye un medio excepcional para subsanar los defectos del procedimiento o para evitar que se vulneren los derechos del administrado consagrados en el Código Tributario, en los casos en que no exista otra vía idónea, ésta no ha sido prevista para que el Tribunal ordene a la Administración pronunciarse sobre solicitudes y/o recursos interpuestos dentro de los plazos establecidos por la ley, pues para ello se ha conferido a los interesados la potestad de impugnar las denegatorias fictas, criterio recogido en las Resoluciones del Tribunal Fiscal $N^{\circ}$ 09293-1-2009 y 11271-7-2009, entre otras.

Sin embargo, de la lectura del artículo 156 del Código Tributario se advierte que no prevé la figura del silencio administrativo negativo como alternativa del recurrente para, ante la falta de pronunciamiento de la Administración dentro del plazo fijado legalmente, acudir a la siguiente instancia (Tribunal Fiscal) con el objetivo de que se pronuncie sobre el fondo de su pretensión. En este orden de ideas, si la Administración no se pronuncia sobre el mandato del Tribunal Fiscal, ¿qué alternativa tiene el recurrente?

Atendiendo a que el artículo 156 citado no concede al recurrente el derecho a acogerse a un silencio administrativo negativo por la falta de pronunciamiento del órgano resolutor de primera instancia, consideramos que queda abierta la puerta para que el recurrente pueda plantear una queja cuestionando la falta de pronunciamiento de la Administración. Ello encuentra expreso amparo legal en lo previsto en el inciso h) del artículo 92 del Código Tributario, según el cual uno de los derechos de los administrados es "interponer queja por omisión o demora en resolver los procedimientos tributarios o por cualquier otro incumplimiento a las normas establecidas en el presente Código", y también en los

21 Por ejemplo, en la Resolución № 00516-Q-2020. 
criterios mencionados del Tribunal Fiscal, que no admite la formulación de queja por demora cuando existe una vía idónea para salvaguardar los derechos del administrado, lo que no ocurre cuando no se cumple con pronunciarse sobre lo ordenado por el Tribunal Fiscal en el plazo fijado en el citado artículo 156.

De esta manera, si la Administración no emite la resolución de cumplimiento en el plazo de 90 días contados desde que se notificó a la Administración la resolución del Tribunal Fiscal, el recurrente puede formular queja contra aquélla, que deberá ser declarada fundada si efectivamente se acredita el incumplimiento.

\section{CONCLUSIONES}

i. El Derecho debe adaptarse a los cambios en las relaciones humanas vinculados a los avances tecnológicos y a una crisis sanitaria global, regulando las nuevas formas de relacionarse, adecuando los principios y normas existentes, pensadas para un contexto de comunicación escrita en papel, a otro contexto muy diferente, donde el uso de las nuevas tecnologías es intensivo y generalizado.

ii. Resulta de vital importancia que las normas sobre domicilio procesal electrónico sean lo más claras posibles, a fin de no perjudicar el derecho de defensa de los administrados, más aún cuando el domicilio procesal electrónico, junto con la notificación electrónica, son dos figuras procesales cuyo uso está camino a generalizarse, especialmente por la COVID-19, a fin de evitar diligencias de notificación presenciales, salvaguardando la salud de notificadores y deudores tributarios.

iii. El pedido de uso de la palabra ante el Tribunal Fiscal debería eliminarse en el caso en que la controversia que se dilucida en la apelación está referida a requisitos de admisibilidad de la reclamación o de la apelación, y en el caso de procedimientos sumarios.

iv. Debería eliminarse la regla solve et repete en la reclamación contra Órdenes de Pago, se alegue o no se alegue la existencia de circunstancias que evidencian la improcedencia de su cobro, fijando en ambos escenarios un mismo plazo para reclamar.

v. Debería incorporarse una lista no taxativa de actos no reclamables, que serviría de manera ilustrativa especialmente a los administrados que no cuentan con asesoría especializada. 
vi. Con respecto a las resoluciones emitidas en cumplimiento de mandatos del Tribunal Fiscal (artículo 156 del Código Tributario), atendiendo a que no se ha previsto la figura del silencio administrativo negativo por la falta de pronunciamiento de la Administración Tributaria sobre lo ordenado por dicho cuerpo colegiado, el recurrente tiene derecho a plantear queja contra la Administración por tal omisión, al no existir una vía regulada para tal efecto.

\section{LISTA DE REFERENCIAS}

Centro Interamericano de Administraciones Tributarias (CIAT). (2020). Las TIC como herramienta estratégica para potenciar la eficiencia de las Administraciones Tributarias. Fundación Bill \& Melinda Gates / CIAT.

Ezeta, S. (2015). La notificación de actos reclamables como materia de impugnación en el procedimiento contencioso tributario. Defensoría del Contribuyente y Usuario Aduanero - Ministerio de Economía y Finanzas.

Martínez, R. (2010). El Procedimiento Administrativo Electrónico en los ordenamientos Peruano y Español. Revista de Derecho Administrativo de la PUCP, 9. http://revistas.pucp.edu.pe/index.php/derechoadministrativo/article/ view/13708/14332

Villegas, H. (2002). Curso de Finanzas, Derecho Financiero y Tributario. 8o Edición actualizada y ampliada. Editorial Astrea. 